\title{
Saúde, Poder Judiciário e sociedade: uma análise de Brasil e Portugal
}

\section{| ${ }^{1}$ Felipe Dutra Asensi |}

Resumo: O objetivo do trabalho é discutir as estratégias e formas de efetivação da saúde como direito, de modo a refletir sobre os limites e possibilidades de utilização de mecanismos estatais e não estatais para sua reivindicação no Brasil e em Portugal. Para tal, foi realizada pesquisa qualitativa e quantitativa para discutir comparativamente os desafios de efetivação do direito à saúde com foco no acesso à justiça e nos repertórios de ação coletiva. Os resultados evidenciam que a complexidade da eleição do mecanismo estatal ou não estatal está fortemente relacionada à cultura jurídica dos cidadãos, além de fatores políticos e econômicos oriundos da estrutura de oportunidades de cada uma das localidades.

> Palavras-chave: Poder Judiciário; direito à saúde; ação coletiva; judicialização da saúde.

\footnotetext{
1 Pós-doutorado em Direito pela Universidade do Estado do Rio de Janeiro (FD/UERJ) em andamento; doutor em Sociologia pelo Instituto de Estudos Sociais e Políticos; professor e coordenador de Publicações da Escola de Direito da Fundação Getúlio Vargas. Endereço eletrônico: felipedm!@yahoo.com.br
}

Recebido em: 11/03/2013 Aprovado em: 19/08/2013 


\section{Introdução: estruturas e culturas}

Reivindicar, contestar, efetivar e exercer. Tais termos são comumente utilizados para possibilitar a compreensão das estratégias de atuação da sociedade civil em relação a seus direitos. $\mathrm{O}$ modo como os indivíduos vivenciam seus direitos pode definir os repertórios de ação coletiva de que dispõem para efetivá-los, e o inverso também pode ser verdadeiro. Esta correferencialidade entre cultura e estrutura pode permitir uma reflexão dinâmica, densa e "inovadora" a respeito das práticas de resistência e reivindicação de direitos numa chave menos polarizada entre estruturalismo e agência. Estruturas importam, assim como a cultura.

Quando se pensa em estratégias de resistência e efetivação de direitos, isso se revela ainda mais importante. Os direitos se encontram no limiar de questôes estruturais (normas jurídicas, instituiçôes jurídicas ou mecanismos formais de canalização de demandas) e culturais (costumes, associativismo, solidariedade...), e sua efetivação depende diretamente de como os atores vivenciam e experienciam essas duas dimensōes correferenciais.

Um exemplo de direito que revela estas questões é o direito à saúde. Por envolver diretamente a integridade física e psíquica dos indivíduos e por estar fortemente incluída entre os deveres do Estado, a saúde permite visualizarmos, de forma bastante contundente, a relação entre estruturas e culturas e de que modo tais dimensões são vivenciadas pelos atores no cotidiano de suas práticas sociais. No caso da saúde, o debate comparativo entre Portugal e Brasil permite discutir a relação entre Estado, sociedade e Judiciário a partir da dimensão da cultura de participação dos cidadãos, das redes de solidariedade que constituem o espaço local e da utilização cada vez mais frequente de mecanismos institucionais e não institucionais. Portanto, o objetivo deste artigo é discutir as estratégias e formas de efetivação da saúde como direito em ambos os países, de modo a refletir sobre os limites e possibilidades de utilização de mecanismos judiciais e extrajudiciais pelos cidadãos.

Parte-se da constatação de que, no Brasil, ocorre uma judicialização volumosa de demandas em saúde, ao passo que, em Portugal, a judicialização é praticamente inexistente. De início, é possível sugerir que tais diferenças ocorrem em função dos padrões sociais e econômicos de cada um desses países, mas a 
complexidade da questão é ainda maior, pois versa sobre a correferencialidade

de estruturas e culturas em cada localidade. O problema que envolve este artigo consiste no seguinte: por que ocorre uma baixa judicialização da saúde em Portugal, ao passo que no Brasil há uma alta judicialização, considerando que em ambos os países temos um arcabouço jurídico-institucional dos sistemas de saúde e de justiça similares?

Deste modo, este texto apresenta o estudo de caso sobre as estratégias de reivindicação do direito à saúde desenvolvidas pelos cidadãos em ambos os países para que, a partir de suas questões específicas, possamos compreender características da relação entre Estado e sociedade que são fundamentais para a própria construção social desse direito.

\section{Estratégia metodológica}

A pesquisa desenvolvida buscou identificar parâmetros, arranjos institucionais e modos de sociabilidades que influem na definição das estratégias dos atores sociais na reivindicação e efetivação do direito à saúde no Brasil e em Portugal, tendo como referencial empírico os anos de 2011 e 2012. A peculiaridade é que o foco não consistiu somente nas pesquisas e relatórios sobre as ações judiciais, mas também nas pesquisas e relatórios sobre a heterogeneidade de práticas sociais desenvolvidas no espaço extrajudicial, que podem propiciar o estabelecimento de outras formas de efetivar direitos em ambos os países. $\mathrm{O}$ argumento central consistiu na assunção de que há outras formas e estratégias de efetivação de direitos estabelecidos pelos atores sociais que não envolvem necessariamente uma judicialização dos conflitos, tais como a mediação extrajudicial, a arbitragem e outras formas de resolução de conflitos.

A eleição do estudo dos casos de Brasil e Portugal ocorreu por uma série de razões, a saber: semelhanças entre os sistemas de saúde e de justiça; disponibilidade de material empírico para analisar congruências e divergências; e interesse em discutir em que medida a relação passada entre "metrópole" e "colônia" pode ter produzido simetrias e assimetrias institucionais e sociais. Compreende-se que esses fatores tenham despertado o interesse por analisar as experiências de ambos os países a seu modo, com o foco nas oportunidades e culturas políticas que lhes são constitutivas. 

possuem uma forma padronizada de se proceder, como ocorre no âmbito judicial, em que se analisam a quantidade de ações propostas, o tempo de tramitação e as demandas das partes envolvidas. No âmbito judicial, os parâmetros processuais, as regras de apresentação de provas e arguição, os limites atinentes à construção da verdade processual são parâmetros padronizados em normas jurídicas, aplicáveis a qualquer indivíduo que ingresse na seara judicial. Diferentemente, no âmbito extrajudicial, observa-se uma pluralidade de práticas e estratégias que não necessariamente se encontram inscritas e determinadas por procedimentos previstos normativamente, tampouco orientadas processualmente por normas estatais. Tais estratégias podem variar desde a existência de redes de solidariedade e informais, até mesmo formas de composição de conflitos, tais como a mediação extrajudicial. De fato, o âmbito extrajudicial pode permitir aos diversos atores um protagonismo mais efetivo e menos visível na definição das regras de resolução dos conflitos e, ainda mais, na condução do processo decisório. Neste sentido, ao se focar nas pesquisas e relatórios sobre as práticas sociais de reivindicação de direitos, com especial enfoque para a saúde, os objetivos do artigo se voltaram para a cultura política e participativa dos cidadãos em ambos os países.

O foco do artigo consistiu na coleta de dados qualitativos e quantitativos, além da análise de pesquisas e relatórios sobre experiências concretas de efetivação de direitos e resolução de conflitos no âmbito institucional e não institucional de ambos os países. Neste contexto, foi fundamental a construção de dimensões analíticas, as quais servem ao propósito de auxiliar a sistematização dos dados e na correspondente análise.

Em outras palavras, foram constituídas três dimensões, que foram consideradas no processo de coleta de dados, quais sejam: (a) concepção de direito subjacente aos diversos atores e instituiçôes presentes no âmbito judicial e extrajudicial (ex.: concepçóes de justiça dos atores; perspectivas sobre o que é o direito, etc.); (b) estratégias institucionais e não institucionais adotadas na interface entre instituições jurídicas, Estado e sociedade civil na efetivação de direitos e resolução de conflitos (ex.: acordos alcançados, negociações travadas e mecanismos de cristalização de consensos); (c) relação concreta entre a esfera extrajudicial e a judicial, ou seja, de que forma os atores que transitam em ambas 
as esferas utilizam os recursos e estratégias de cada uma delas, de modo a efetivar

direitos e resolver conflitos (ex.: incorporação de procedimentos judiciais no âmbito extrajudicial; utilização da via judicial como último recurso e outros).

A escolha das técnicas de pesquisa permite justamente minimizar o impacto das múltiplas dimensões que podem ser abarcadas em um estudo de caso. A triangulação dos métodos pode auxiliar na redução de vieses e na correta adequação da análise das estratégias desenvolvidas pelos atores sociais. Portanto, no artigo foram privilegiadas duas técnicas, que se coadunam como fontes secundárias de pesquisa:

a) Análise de documentos institucionais: com ênfase nos conselhos participativos, instituiçōes jurídicas e sanitárias, documentos do governo e relatórios internacionais de ambos os países. De Portugal, por exemplo, foram utilizados os relatórios do Observatório Português dos Sistemas de Saúde - especialmente o Relatório Primavera 2011 e 2012; do Centro de Estudos Sociais da Universidade de Coimbra, do Ministério da Saúde, da Provedoria de Justiça e outros. Do Brasil, por exemplo, foram utilizados os relatórios do Conselho Nacional de Saúde, Ministério da Saúde e Conselho Nacional de Justiça. Além disso, também foram utilizados relatórios da Organização Mundial da Saúde sobre ambos os países.

b) Pesquisas quantitativas e qualitativas sobre Judiciário, sistemas de saúde e cultura de participação em ambos os paises: de Portugal, por exemplo, foram utilizados resultados de pesquisas empíricas desenvolvidas no Centro de Estudos Sociais da Universidade de Coimbra, do Centro de Investigação Estudos de Sociologia do Instituto Universitário de Lisboa e outros. Do Brasil, por exemplo, foram utilizados resultados de pesquisas empíricas desenvolvidas pelo Laboratório de Pesquisas sobre Práticas de Integralidade em Saúde, da Fundação Oswaldo Cruz e do Conselho Nacional de Justiça.

A pertinência da pesquisa encontra-se diretamente relacionada à necessidade de se estudar, pesquisar e refletir sobre os espaços, dinâmicas e estratégias institucionais e não institucionais que se desenvolvem a seu modo, em ambos os países, como oportunidades políticas. 


\section{Resultados}

Considerando o exposto, podemos então discutir as diferenças nas estratégias de reivindicação do direito à saúde em Brasil e em Portugal - com foco especial na utilização das instituições jurídicas pelos cidadãos - a partir das pesquisas e relatórios utilizados. Indo além, é possível pensar os condicionantes que influenciam a diversificação de estratégias em ambos os países, de modo a refletir sobre as variáveis políticas, econômicas e culturais que influem na constituição de estratégias reivindicativas ou de contestação. Inicialmente, as estratégias de reivindicação e contestação são distintas porque há incentivos e condicionantes que influenciam a ação dos atores sociais em ambos os países e, portanto, influem nas estratégias dos atores na efetivação do direito à saúde. Tais condicionantes envolvem três tipos de relaçôes:

a) saúde e solidariedade: o modo como os indivíduos concebem o dever do Estado de implementar satisfatoriamente os serviços de saúde e a responsabilização do indivíduo pela sua própria saúde, o que produz forte influência na utilização de espaços institucionais e de redes de solidariedade. Admite-se que há diferenças no que concerne aos itinerários do cuidado em saúde, ora enfatizando a centralidade do Estado no cuidado (Brasil), ora responsabilizando o indivíduo pela sua própria saúde (Portugal), o que enseja impactos na própria cultura de participação dos indivíduos em ambos os países e a utilização de espaços institucionais e não institucionais;

b) participação social e cultura política: o modo como os indivíduos participam do processo de formulação, execução e fiscalização das políticas de saúde em espaços institucionais e não institucionais, além da própria cultura política historicamente constituída e variada entre os países. Admite-se que os sistemas de saúde de ambos os países foram construídos por influência predominantemente internacional (Portugal) ou dos movimentos sociais (Brasil), de modo que isto permitiu constituir em cada um destes países formas distintas de lidar com o direito à saúde pelos cidadãos;

c) judicialização e desjudicialização: o modo como os indivíduos concebem o Judiciário como efetivador de direitos e as estratégias que adotam para veicular reivindicações e demandas em saúde. Admite-se que há diferenças no que concerne à relação ente Judiciário e sociedade, ora estabelecendo 
políticas de proximidade com o cidadão (Brasil), ora estabelecendo políticas

de desjudicialização (Portugal), o que enseja repercussões na própria forma como os indivíduos concebem o sistema judicial e o ativam em seu cotidiano.

De antemão, podemos salientar algumas similaridades nos sistemas de saúde de ambos os países, quais sejam:

- Saúde é um direito constitucional: pode-se observar que a saúde figura como direito constitucional previsto no Brasil e em Portugal, ensejando a necessidade do desenvolvimento de um sistema de saúde que dê conta, em alguma medida, da topografia constitucional deste direito. Porém, isto não quer dizer que a força normativa da Constituição se expresse da mesma forma em ambos os países. A topografia constitucional do direito à saúde no Brasil reforçou a exigibilidade de tal direito sobremaneira, ao passo que em Portugal a topografia constitucional não se expressa como argumento jurídico (político, social ou cultural) relevante. ${ }^{1}$

- Sistemas de saúde são contemporâneos: em que pese terem se solidificado em momentos históricos relativamente distintos (décadas de 1940 e 50 em Portugal e de 1980 e 90 no Brasil), é possível afirmar que os sistemas de saúde são verdadeiramente contemporâneos. A qualificação de "contemporâneos" não diz respeito somente à temporalidade em que foram constituídos, mas às próprias características de tais sistemas: universalização, participação social, serviços de baixa, média e alta complexidade e regionalização.

- Sistemas de saúde universais e públicos: a universalização e o caráter público são características definidoras de ambos os sistemas de saúde. No entanto, isto não quer dizer que a universalização ou caráter público não tenham desafios para sua efetivação. No Brasil, por exemplo, a universalização a 190 milhões de brasileiros ensejou desafios econômicos e institucionais para a administração em saúde. Além disso, o caráter público da saúde veio acompanhado, pelo menos em serviços de baixa e média complexidade, de relativa precarização. Em Portugal, a universalização esteve amplamente condicionada às políticas de governo, o que legitimou o estabelecimento de políticas de restrição da saúde no país. Ademais, o caráter público veio acompanhado de uma desvinculação de qualquer gratuidade, com a introdução das taxas moderadoras, além de também incorporar uma diversidade de subsistemas de saúde públicos e privados. ${ }^{2}$ 
- Pressupõem participação social: em ambos os países, a consolidação dos sistemas de saúde veio acompanhada de ideários de participação social, em que a sociedade civil teria a possibilidade de participar e influir diretamente o processo de formulação, execução e fiscalização das políticas de saúde. No Brasil, esta participação se desenvolveu de forma privilegiada em espaços institucionalizados estatais, com foco especial nos Conselhos e Conferências de Saúde. Os dilemas da participação ${ }^{3}$ dizem respeito, por exemplo, à cooptação dos usuários pelos grupos políticos mais coesos que participam do Conselho e à divulgação das atividades do Conselho e da Conferência. Em Portugal, a participação desenvolveuse em espaços predominantemente informais. Os espaços formais, a exemplo do Conselho Nacional de Saúde Mental, receberam pouca adesão popular, e as estratégias de reivindicação da saúde em geral se desenvolvem por meio de protestos ou reclamaçōes individuais. ${ }^{4}$

- Promovem regionalização dos serviços: uma das principais estratégias contemporâneas de universalização dos sistemas de saúde consiste em aliar a participação social com a regionalização dos serviços. No caso brasileiro, a regionalização foi ainda intensificada com estratégias de descentralização político-administrativa, que conferiram à União, estados e sobretudo municípios a responsabilidade de promover políticas de saúde. A esta descentralização foi constituída paralelamente uma descentralização da participação, com Conselhos e Conferências de Saúde presentes nos três níveis de governo. Em Portugal, a estratégia consistiu na regionalização por si só, que foi operada por meio de uma divisão administrativa realizada pelo governo português com base numa racionalidade gerencial de alocação de recursos e análise populacional. Às regiōes não foram atreladas quaisquer instâncias participativas efetivas que conferissem algum tipo de legitimidade democrática às decisões.

No caso dos sistemas judiciários - que envolvem não somente o Poder Judiciário, mas as instituições jurídicas correlatas, como o Ministério Público também é possível elencar semelhanças em ambos os países, tais como:

- Estrutura hierarquizada e burocratizada: a estrutura judiciária densa e com diversidade de cargos e funções faz com que a figura do magistrado se constitua de forma "anônima". Isto porque, ao restar imerso na estrutura e hierarquia do Judiciário, o juiz - principalmente o de 1a instância - recebe pouco protagonismo 
e destaque no Judiciário nacional. No Brasil, assim como em Portugal, os magistrados que ocupam destaque político e social são os de tribunais superiores e ministros de cortes constitucionais, de modo que a estrutura burocratizada vem acompanhada de uma hierarquia que frustra e torna anônimo o juiz de $1^{\text {a }}$ instância. A diferença é que, no Brasil, a burocracia judicial é ancorada no cânone da independência em relação aos demais poderes, e isto se reforça com a criação do Conselho Nacional de Justiça como estrutura inserida no Poder Judiciário e responsável por sua administração nacional. Em Portugal, a burocracia judicial, ao menos do ponto de vista administrativo, encontra-se fortemente influenciada pelas políticas de governo. A criação da Direcção-Geral de Administração da Justiça, vinculada ao Poder Executivo, é reveladora dessa influência.

- Tradição de civil law: inseridos na tradição de civil law, as instituições jurídicas de Brasil e Portugal revelam forte apego às normas jurídicas escritas como fontes primárias do direito, situando em segundo plano os costumes, por exemplo. A tradição de civil law faz com que estes países confiram forte centralidade à lei e, portanto, boa parte da transformação social se opera, por definição, por uma transformação legal, apesar de o inverso também ser verdadeiro.

- Law in books $x$ law in action: em ambos os países, o direito construído por meio de normas predominantemente escritas pode revelar uma afeição por normas abstratas que podem ser insensíveis às peculiaridades sociais, culturais e políticas de cada um dos países. $\mathrm{O}$ apego à abstração, em países de tradição de civil law, enseja a necessidade de dar algum tipo de concretude às normas jurídicas. No cenário de efetivação de direitos brasileiro, o Judiciário é ator privilegiado para conferir esta concretude; em Portugal, temos o protagonismo do governo.

- Ingresso predominante por meritocracia: a meritocracia é critério predominante para ingresso na carreira da magistratura no Brasil e em Portugal. Isto permite constituir um segmento de poder exercido pelos magistrados. No caso brasileiro, podemos pensar num contexto fortemente judicializante a respeito dos mais diversos assuntos, inclusive a saúde. No caso português, quanto mais os atores agem extrajudicialmente no cotidiano de suas práticas sociais, maior é a ideia de que o Judiciário não é o ator privilegiado para a resolução de conflitos e efetivação de direitos, inclusive na saúde. 
- Obstáculos de acesso à justiça e ao direito: tanto em Portugal quanto no Brasil, podemos observar desafios e obstáculos socioculturais e econômicos de acesso à justiça e ao direito. Não somente em relação aos próprios mecanismos institucionais de efetivação dos direitos, mas aos próprios direitos, podemos observar obstáculos que se revelam de forma relativamente acentuada em ambos os países. Porém, no Brasil, observam-se políticas públicas que buscam reduzir os déficits de uma sociedade civil historicamente marginalizada aos serviços jurídicos estatais, tais como a gratuidade de justiça e a Defensoria Pública, o que contribui fortemente para a judicialização dos conflitos. Em Portugal, a histórica separação entre Estado e sociedade, associada à própria cultura extrajudicial dos cidadãos, fez com que a judicialização fosse bastante inexpressiva. No Brasil, caminhou-se de um "fechamento" judicial para a judicialização radical e, em Portugal, ocorreu justamente o inverso.

A despeito das aproximaçôes aqui descritas, podemos assumir que a realidade de efetivação e reivindicação do direito à saúde pode se diferenciar a partir de diversas variáveis, tais como: social, cultural, geográfica, recursos humanos, qualidade dos serviços públicos, influência dos governos, itinerários dos cuidados em saúde e inserção do Judiciário. Entre tais variáveis, podemos elencar que as duas últimas recebem protagonismo e destaque no cotidiano das instituições jurídicas e sanitárias destes países. De um lado, os itinerários dos cuidados em saúde desenvolvidos em ambos os países revelam os incentivos e performances estatais e não estatais que os cidadãos adotam para promoverem sua própria saúde, cuja escolha se encontra com frequência influenciada por aspectos culturais, sociais e governamentais. De outro, a inserção do Judiciário na sociedade como um efetivador de direitos também é fundamental para pensar a forma como os cidadãos concebem e ativam esse Poder no Brasil e em Portugal. Articulando as duas variáveis, temos a seguinte análise idealtípica: 


\begin{tabular}{|c|c|c|c|c|}
\hline & & Dimensão política & Dimensão social & $\begin{array}{c}\text { Dimensão } \\
\text { governamental }\end{array}$ \\
\hline \multirow{2}{*}{$\begin{array}{l}\text { Itinerário } \\
\text { dos } \\
\text { cuidados } \\
\text { em saúde }\end{array}$} & Brasil & $\begin{array}{l}\text { A relação entre os } \\
\text { três poderes é de } \\
\text { forte interpenetração, } \\
\text { de modo que todos } \\
\text { participam ativamente } \\
\text { na construção das } \\
\text { políticas de saúde e } \\
\text { efetivação de direitos. }\end{array}$ & $\begin{array}{l}\text { Recebe forte influência } \\
\text { da participação } \\
\text { social, que se } \\
\text { desenvolve de maneira } \\
\text { perene, sobretudo } \\
\text { em mecanismos } \\
\text { institucionais (Conselhos } \\
\text { e Conferências). }\end{array}$ & $\begin{array}{l}\text { Forte dependência } \\
\text { das políticas } \\
\text { governamentais, mas } \\
\text { com ampla participação } \\
\text { social com mecanismos } \\
\text { institucionais. }\end{array}$ \\
\hline & Portugal & $\begin{array}{l}\text { A relação entre os três } \\
\text { poderes é de pouca } \\
\text { interpenetração mútua, } \\
\text { com protagonismo } \\
\text { do Poder Executivo } \\
\text { na construção das } \\
\text { políticas de saúde e de } \\
\text { justiça e na efetivação } \\
\text { de direitos. }\end{array}$ & $\begin{array}{l}\text { Recebe baixa influência } \\
\text { da participação social } \\
\text { formal que, quando } \\
\text { se desenvolve, o faz } \\
\text { em mecanismos não } \\
\text { institucionais (protestos, } \\
\text { reclamações, etc.) e de } \\
\text { forma pontual e eventual. }\end{array}$ & $\begin{array}{l}\text { Forte dependência } \\
\text { das políticas } \\
\text { governamentais, mas } \\
\text { com baixa participação } \\
\text { social em mecanismos } \\
\text { institucionais. }\end{array}$ \\
\hline \multirow{2}{*}{$\begin{array}{l}\text { Inserção } \\
\text { do } \\
\text { Judiciário }\end{array}$} & Brasil & $\begin{array}{l}\text { Judiciário como ator } \\
\text { privilegiado e com } \\
\text { legitimidade formal } \\
\text { para efetivar os } \\
\text { direitos, a despeito dos } \\
\text { obstáculos de acesso à } \\
\text { justiça e ao direito. }\end{array}$ & $\begin{array}{l}\text { A forte judicialização } \\
\text { das relações sociais } \\
\text { encontra-se ancorada na } \\
\text { percepção dos cidadãos } \\
\text { do Judiciário como forma } \\
\text { privilegiada de resolução } \\
\text { de conflitos e efetivação } \\
\text { de direitos (pirâmide de } \\
\text { litigiosidade com base } \\
\text { pequena). }\end{array}$ & $\begin{array}{l}\text { Baixa influência } \\
\text { do governo na } \\
\text { determinação da } \\
\text { atividade administrativa } \\
\text { e gerencial do Judiciário, } \\
\text { além de as políticas } \\
\text { de governo serem } \\
\text { amplamente suscetíveis } \\
\text { ao controle judicial. }\end{array}$ \\
\hline & Portugal & $\begin{array}{l}\text { Judiciário } \\
\text { historicamente } \\
\text { afastado da sociedade } \\
\text { civil e, a despeito da } \\
\text { legitimidade formal, } \\
\text { os obstáculos de acesso } \\
\text { à justiça e ao direito } \\
\text { se apresentam como } \\
\text { condicionantes da } \\
\text { baixa litigação. }\end{array}$ & $\begin{array}{l}\text { A pouca recorrência } \\
\text { social dos indivíduos ao } \\
\text { Judiciário faz com que a } \\
\text { opção extrajudicial não } \\
\text { institucional passe a ser } \\
\text { estratégia privilegiada } \\
\text { de efetivação da saúde } \\
\text { (pirâmide de litigiosidade } \\
\text { com base grande). }\end{array}$ & $\begin{array}{l}\text { Forte influência } \\
\text { do governo na } \\
\text { determinação da } \\
\text { atividade administrativa } \\
\text { e gerencial do Judiciário, } \\
\text { acompanhada de baixa } \\
\text { influência do Judiciário } \\
\text { no controle das políticas } \\
\text { de governo. }\end{array}$ \\
\hline
\end{tabular}




\section{Discussão}

No Brasil, a estratégia predominantemente institucional de reivindicação do direito à saúde esteve fortemente relacionada à constituição de uma cultura política de participação da sociedade no processo de planejamento, execução e fiscalização das políticas de saúde. Fruto das demandas oriundas de movimentos sociais, cujo mais representativo é o movimento de reforma sanitária, as políticas de saúde no Brasil foram permeadas e fortemente influenciadas pela sociedade civil nos diversos espaços públicos de participação, sobretudo os Conselhos e Conferências de Saúde. ${ }^{5}$

Gradativamente, o espaço da representação parlamentar passou a conviver com outros espaços representativos que trouxeram, em seu interior, a missão de democratizar radicalmente a política de saúde, de um lado, e de fomentar a construção social das políticas, de outro. Porém, também gradativamente os espaços de representação do parlamento e dos Conselhos e Conferências passaram a conviver com mais um espaço de efetivação de direitos: o Judiciário.

Tribunais, promotorias, defensorias e outras instituições jurídicas têm sido cada vez mais presentes no cotidiano das estratégias dos cidadãos na efetivação da saúde. Dentre tantos motivos, isso ocorre porque tais instituições têm recebido maior protagonismo e se apresentam como oportunidades políticas de reivindicação e efetivação de direitos. A progressiva constitucionalização por que os direitos sociais passaram na década de 1980 em diante no Brasil, associada aos desafios de implementação efetiva por parte do Estado, fez com que tais direitos fossem cada vez mais submetidos ao crivo dessas instituiçôes para a obtenção do mandamento de efetivação. A judicialização do direito à saúde, mais especificamente, tem versado sobre diversos serviços públicos, tais como o fornecimento de medicamentos, a disponibilização de exames e a cobertura de tratamentos para doenças. ${ }^{6}$

Em algumas localidades no Brasil, ${ }^{7}$ as instituições jurídicas têm até se apresentado como um espaço de diálogo, pois passam a possibilitar a comunicação entre os principais atores que compõem o processo de formulação, gestão e fiscalização das políticas públicas em saúde em um foro comum. Portanto, no cotidiano da efetivação do direito à saúde brasileiro, temos o protagonismo decisivo das instituições jurídicas, o que influi decisivamente na forma como os atores sociais reivindicam esse direito. 
A cultura de reivindicação de direitos no Brasil, em função do componente centrado no Estado, que faz parte de sua constituição sociológica, passou a incorporar as instituições jurídicas e, em especial, o Judiciário como estratégia privilegiada de boa parte da população. ${ }^{8}$ Quando mais se acreditou que o Judiciário seria um ator privilegiado na efetivação da saúde, maior foi seu fortalecimento institucional interno (de forma corporativa) e externo (com a judicialização da saúde). As esferas representativas ou participativas que se constituíram na saúde passaram a conviver com a esfera judicial, que ocupou um espaço privilegiado - apesar de não exclusivo - na efetivação do direito à saúde. Atualmente, as instituições jurídicas têm atuado não somente na implementação de políticas públicas de saúde em voga, mas também no reconhecimento de direitos demandados pelos cidadãos, tais como: operações para mudança de sexo, autorização de mudança de nomes de transexuais, saúde do homem e da mulher, autorização para realização de cirurgia bariátrica, reconhecimento de aposentadoria e planos de saúde para dependentes em união estável, saúde indígena e outros.

Este protagonismo das instituições jurídicas não esteve isento de contradições no Brasil. São exemplos de contradições os obstáculos de acesso à justiça e ao direito, que contribuem para uma relativa "colonização" da judicialização da saúde, ao menos de forma predominante, por um determinado perfil socioeconômico. Outro exemplo é a própria discussão a respeito das consequências econômicas das decisões judiciais. Exames, tratamentos e medicamentos, principalmente se forem excepcionais, trazem em seu bojo, quando deferidos judicialmente, a necessidade de fornecimento sem necessariamente haver um planejamento de governo. Independentemente de isso ser bom ou ruim, o fato é que a judicialização da saúde no Brasil tem reconfigurado drasticamente as responsabilidades dos Poderes para o estabelecimento de políticas públicas que atendam aos critérios de universalidade, integralidade e descentralização.

Em Portugal, os mecanismos de efetivação da saúde são marcadamente não institucionais e, portanto, mais heterogêneos. Não é incomum observar uma série de protestos, levantes, cartas e boicotes que caracterizam decisivamente o processo de reivindicação do direito à saúde. ${ }^{2}$ A despeito da existência de uma série de elementos em comum com o Brasil - como participação, descentralização e universalização -, em Portugal a cultura política dos 
cidadãos foi constituída numa perspectiva de afastamento institucional entre Estado e sociedade, principalmente na saúde.

Os espaços representativos do parlamento e dos mecanismos de participação foram se enfraquecendo e perdendo força normativa. No caso do parlamento, isto ocorreu em função do sistema parlamentarista, que confere ao Primeiro Ministro proeminência na definição das políticas e na introdução da racionalidade econômica e administrativa na sua implementação. No caso dos mecanismos de participação - como o Conselho de Saúde - isto é ainda mais evidente porque, a despeito da previsão normativa da criação de Conselhos de Saúde em Portugal, estes jamais foram implementados.

Segundo Santos, isto ocorre porque as deficiências de produção estatal de saúde e segurança social são em parte compensadas pela sociedade-providência. Em função de seu aspecto fortemente ruralista e das assimetrias regionais, a sociedade "adestrou-se" a não depender do Estado no que concerne aos cuidados em saúde, ao inverso do que ocorreu com a urbanização brasileira. Deste modo, o que caracteriza a sociedade portuguesa é a "forte presença da medicina popular de produção artesanal ao lado da medicina oficial e funcionando como mecanismo compensatório das deficiências da medicina estatal ou da inacessibilidade da medicina privada" (SANTOS, 1987, p. 32-33). Além disso, o ideal da participação em Portugal recebeu pouco destaque no âmbito do EstadoProvidência e no âmbito da sociedade-providência. De fato, "os serviços centrais ignoravam, na prática, as Comissões Integradoras dos Serviços de Saúde” (Idem, p. 36). Isto ocorreu por conta da tradição autoritária do Estado português, mas também por conta do déficit de organicidade da sociedade em partidos ou em vias institucionais, o que permitiu ao Estado desenvolver autonomamente as políticas sem incorporação popular.

Em Portugal, a interação entre Estado e sociedade civil tornou-se extremamente pontual na saúde, de modo que os mecanismos institucionais de efetivação da saúde passaram a conviver com mecanismos societários construídos a partir da interação comunitária da sociedade-providência. O resultado é que os protestos, em sentido amplo, se tornaram a principal estratégia de interseção entre Estado e sociedade. Porém, esta cultura de protestos de boa parte da população passou a conviver com as diversas práticas sociais orientadas pela medicina paralela, a entreajuda e a solidariedade. 
Não obstante, ainda é possível ressaltar um efeito político da participação de Portugal na União Europeia: a livre circulação de pessoas e, consequentemente, a livre utilização dos serviços de saúde pelos cidadãos europeus. Com o ingresso de Portugal na União Europeia, observa-se uma migração significativa de portugueses para outros países, mas também se observa o que Carapinheiro e Page (2002) denominam como "circulação seletiva de consumidores". Mais precisamente, sendo cidadão europeu, o cidadão português passa a ter acesso a uma pluralidade de serviços de saúde em todo o continente, o que contribui para a própria redução do papel do Estado português na efetivação da saúde, sobretudo nos países fronteiriços, que passam a receber migrações pontuais, temporárias e voltadas para o consumo de serviços de saúde.

Em ambos os países, não podemos de modo algum afirmar que há uma apatia política da sociedade civil em relação ao Estado e às políticas de saúde. O que se observa, na verdade, é a complexidade que envolve a interação entre culturas e estruturas, cujo resultado é uma miríade de estratégias de reivindicações de direitos. Indo além, é fundamental reconhecer que a judicialização do direito à saúde e dos serviços públicos que lhes são correlatos não significa, necessariamente, que as relações sociais estão se judicializando. No Brasil, por exemplo, em meio à constitucionalização dos diversos direitos sociais ao longo do século XX, de um lado, e à insuficiência das políticas públicas para implementálos efetivamente, a estratégia judicial tem sido frequente na determinação de medicamentos, tratamentos e exames. Observa-se a judicialização dos direitos e, mais propriamente, do direito à saúde. Isto evidencia que o Judiciário e os direitos não são necessariamente "faces de uma mesma moeda", pois, a depender das dinâmicas societárias, essa relação pode não acontecer.

Com base nisto, é possível sustentar que as estratégias de reivindicação de direitos, no caso da saúde, estão fortemente orientadas pelos incentivos e restrições advindos dos sistemas de saúde e dos sistemas de justiça de ambos os países. Isto produz repercussões diretas na forma como os cidadãos concebem e vivem seus direitos e na cultura de participação e reivindicação que eles desenvolvem no cotidiano de suas práticas sociais. Além disso, a relação entre estrutura e cultura permite pensar por que, no Brasil, há forte judicialização da saúde, ao passo que em Portugal este processo é praticamente inexistente. Inseridos na cultura 
política de cada localidade e submetidos às restriçõos e incentivos específicos, os cidadãos ativam-nas com base em variáveis estratégicas que vão além da similaridade normativa e institucional que existe entre os dois países.

\section{Considerações finais}

Este artigo buscou refletir sobre como os indivíduos experienciam seu direito à saúde e de que forma, a partir de sua compreensão, ativam mecanismos institucionais e não institucionais de efetivação. Tal compreensão se encontra orientada, de um lado, pela cultura política de uma sociedade e, de outro, pelas estruturas de saúde e de justiça que lhes são subjacentes. A efetivação da saúde como direito encontra desafios dos mais diversos, que versam não somente sobre a relação entre os indivíduos e o Estado, mas, sobretudo, sobre a própria forma como os indivíduos reivindicam seus direitos.

O resultado foi que, ao lado de um direito oficial e estatalizado, observa-se um direito vivo em saúde que, em função de sua heterogeneidade e dinamicidade, revela as contradiçỗes fundamentais da relação entre Estado e sociedade civil. De fato, assim como o direito não se reduz à lei, o ator que efetiva direitos não é somente o magistrado. O que se observa é uma pluralidade de instituições, atores e intérpretes que também atuam decisiva e legitimamente na construção e garantia de direitos no Brasil e em Portugal. O Judiciário, portanto, pode se apresentar somente como mais um desses atores, cuja aparente proeminência advém de suas competências e atribuições constitucionais, principalmente no que concerne à resolução de conflitos.

Os espaços extrajudiciais têm adotado, por vezes, estratégias de mediação, pactuação e negociação fundamentalmente céleres e que visam, em certa medida, atuar na efetivação de direitos existentes e na construção de novos direitos. Isso reconfigura e tensiona a própria perspectiva de judicialização e chama atenção, de forma bastante clara, para as atuaçóes extrajudiciais constituídas a partir das práticas sociais. $\mathrm{O}$ âmbito extrajudicial pode inaugurar e conferir realce a outros personagens que, em virtude de suas estratégias de ação, são decisivos na efetivação dos direitos, ganhando relevo as interaçōes sociais. No Brasil, o Judiciário tende a se fortalecer cada vez mais na saúde, ao passo que, em Portugal, observa-se o fortalecimento das práticas extrajudiciais. Logicamente, isto não quer dizer que em ambos os países não tenhamos movimentos no sentido inverso, apesar 
de não se tratar de uma tendência. É neste processo contraditório entre cultura e estrutura, sociedade e Estado e judicial e extrajudicial que se constituem as oportunidades políticas de efetivação do direito à saúde.

\section{Agradecimentos}

Ao Centro de Estudos Sociais da Universidade de Coimbra, pelo apoio financeiro para a realização da pesquisa, em especial aos professores Mauro Serapioni, Silvia Portugal e Boaventura de Sousa Santos.

\section{Referências}

ASENSI, F. Indo além da judicialização: o Ministério Público e a saúde no Brasil. Rio Janeiro: FGV, 2010.

. Direito à saúde. Curitiba: Juruá, 2013.

BRASIL. Constituição da República Federativa do Brasil. Brasília: Senado Federal, 1988.

CARAPINHEIRO, G.; PAGE, P. As determinantes globais do sistema de saúde português. In: HESPANHA, P.; CARAPINHEIRO, G. (Orgs.). Risco social e incerteza: pode o estado social recurar mais? Porto: Afrontamento, 2002. p. 81-122.

DUARTE, M. Entre o radicalismo e a contenção: o papel do direito na campanha Women on Waves em Portugal. Oficina do CES, n. 279, 29 p., 2007.

FUKS, M. Participação e influência política no conselho municipal de saúde de Curitiba. Revi Soc Politica, v. 25, p. 47 - 61, 2005.

GERSCHMAN, S. Conselhos municipais de saúde: atuação e representação das comunidades populares. Cad de Saude Pública, v. 20, n. 6, p. 1670-1681, 2004.

GUIZARDI, F.; PINHEIRO, R. Dilemas culturais, sociais e políticos da participação dos movimentos sociais nos Conselhos de Saúde. Cien Saude Colet, v. 11, n. 03, p. 797-805, 2006.

GUIZARDI, F. et al. Participação da comunidade em espaços públicos de saúde: uma análise das Conferências Nacionais de Saúde. Physis: Revista de Saúde Coletiva. Rio de Janeiro, v. 14, n. 1, p. 15-39, 2004.

MATOS, A. A importância da participação cidadã nas políticas de saúde: o caso da reestruturação dos serviços de saúde materno-infantil em Portugal. Saúde e Sociedade, v. 20, n. 3, p. 604-616, 2011.

MENDES, J. Só é vencido quem deixa de lutar: protesto e Estado democrático em Portugal. Rev Crit Cien Sociais, n. 72, p. 161-185, 2005.

MENDES, J.; SEIXAS, A. Acção coletiva e protesto em Portugal: os movimentos sociais ao espelho dos media (1992-2002). Rev Crit Cien Sociais, n. 72, p. 99-127, 2005. 

de saúde: solução que se transformou em problema?. Saúde e Sociedade, v. 15, n. 49-57, 2006. NUNES, J. Saúde, direito à saúde e justiça sanitária. Rev Crit Cienc Sociais, n. 87, p. 143$169,2009$.

OLIVEIRA, L.; PINHEIRO, R. A participação nos conselhos de saúde e sua interface com a cultura política. Cien Saude Colet, v. 15, n. 5, p. 2455-2464, 2010.

SANTOS, B. Estado, sociedade, políticas sociais: o caso da política de saúde. Rev Crit Cien Sociais, n. 23, p. 13-74, 1987.

SEIXAS, A. Aprender a democracia: jovens e protesto no ensino secundário em Portugal. Rev Crit Cien Sociais, n. 72, p. 187-209, 2005.

SERAPIONI, M. Il sistema sanitario portoghese. Salute Internazionale [periódico na internet]. 2010. Disponível em: http://saluteinternazionale.info/2010/09/il-sistemasanitario-portoghese/ Acesso: set. 2010.

SERAPIONI, M.; ROMANÍ, O. Potencialidades e desafios em instâncias colegiadas dos sistemas de saúde - os casos da Itália, Inglaterra e Brasil. Cad de Saude Publica, v.22, n.11, p.2411-2421, 2006.

SERAPIONI, M.; SESMA, D. A participação dos cidadãos nos sistemas de saúde da Europa do Sul: Portugal, Itália e Espanha. Resultados preliminares de um estudo comparativo. Sociologia Online, n.2, p.599-629, 2001.

\section{Notas}

${ }^{1}$ No Brasil, com a Constituição de 1988 e as intensas reivindicações de uma pluralidade de grupos sociais e políticos, a saúde foi alçada à categoria de direito fundamental, cujo imperativo é a prestação positiva do Estado no sentido de concretizá-la e ampliá-la a todos os cidadãos. A universalização da saúde foi acompanhada de sua institucionalização normativa, o que possibilitou a cristalização de princípios, normas e diretrizes que seriam desenvolvidos nos anos seguintes, cuja expressão mais significativa foi a criação do Sistema Único de Saúde (SUS). Em seu artigo 196, a Constituição estabelece que a saúde é um "direito de todos e dever do Estado" (BRASIL, 1988), o que denota a pretensão universalizante desse direito. Aqui, a saúde é caracterizada como um direito fundamental e dever do Estado, o que denota uma dupla-dimensão (direito-dever) em sua natureza. Em Portugal, pela leitura do texto constitucional, podemos observar que o modelo racionalizador e governamental encontra-se presente e, inclusive, restringiu a própria possibilidade de o cidadão conceber seu direito como um dever do Estado. De fato, sobretudo em função das diversas revisões que passou desde 1976, a Constituição portuguesa passou a ter uma marginalidade jurídica no processo de efetivação da saúde em Portugal. João Nunes, por exemplo, salienta que falar da saúde como direito implica algo que está para além do domínio estrito do direito e que nos conduz a um terreno distinto, marcado por controvérsias, lutas e derivas que não passam (apenas) pelo domínio do direito à saúde: o da consagração da saúde como um direito fundamental ou um dos direitos humanos, referido no art. 25 da Declaração Universal dos Direitos Humanos (NUNES, 2009, p. 143). Deste modo, é possível sustentar que o status normativo da saúde encontra-se, por exemplo, mais relacionado à Declaração de Direitos da ONU do que propriamente à Constituição. 
${ }^{2}$ Conforme salienta Serapioni (2010), existem seis subsistemas sanitários em Portugal que, em conjunto com o Sistema Nacional de Saúde, podem influenciar na saúde da população, quais sejam: o setor da seguridade sanitária pública, que é totalmente dependente da administração pública (cerca de $10 \%$ da população); a seguridade sanitária voluntária, cuja população beneficiária é cerca de $10 \%$, que engloba a oferta dos trabalhadores e dos contratos assecuratórios estipulados individualmente; a seguridade sanitária privada dos dependentes das telecomunicações e dos correios; o subsistema dos funcionários dos bancos e sua seguridade; o sistema assecuratório privado ofertado pelas organizações sem fins lucrativos que contam com cerca de 7\% da população; e as despesas diretas da família (out-of-pocket).

${ }^{3}$ Os desafios participação em saúde no Brasil foram objeto de diversas pesquisas. De um lado, observam-se espaços institucionais estatais que são amplamente utilizados pelos cidadãos e, de outro, observa-se relativa seletividade da utilização de tais espaços, considerando a cultura política e as estratégias de reivindicação do direito à saúde. A este respeito, destacam-se as pesquisas de Gerschman (2004), Guizardi et al. (2004), Fuks (2005), Guizardi \& Pinheiro (2006), Morita, Guimarães e Muzio (2006), Serapioni \& Romaní (2006) e Oliveira \& Pinheiro (2010).

${ }^{4}$ Segundo Serapioni e Sesma, uma característica comum aos países da "Europa do Sul" (Portugal, Espanha e Itália) diz respeito ao "inadequado grau dos direitos garantidos aos utentes pelo respectivo sistema de saúde” (SERAPIONI; SESMA, 2001, p. 607). Os autores salientam que o relatório Health Consumer Powerhouse, de 2009, utilizou quatro dimensōes (direito às informações, possibilidade de escolha dos prestadores, envolvimento ativo e incentivos financeiros) e uma série de indicadores que culminaram no Europatient Empowerment Index para analisar a saúde nesses países. Este índice tem o propósito de avaliar o nível de empowerment (empoderamento) dos doentes dos 27 países da União Europeia. Os resultados "assinalam a necessidade dos sistemas de saúde da Europa do Sul de reduzir o gap, na área dos direitos dos pacientes, da informação e da participação, com os países da Europa continental, da Europa Escandinava e até com alguns países da Europa do Leste” (Idem).

${ }^{5}$ Vale ressaltar que, sob influência das reivindicações do movimento sanitário e de diversos grupos e associaçôes da sociedade civil, foi promulgada a Lei no $8.142 / 90$, que consolidou espaços públicos de participação da sociedade civil na saúde, com a regulamentação dos Conselhos de Saúde e Conferências de Saúde. Tais espaços são relevantes para a continuidade do processo de garantia e efetivação do direito à saúde, sobretudo porque pressupōem uma horizontalização da relação Estado-sociedade.

${ }^{6}$ Segundo o Conselho Nacional de Justiça (CNJ), foram propostos cerca de 240.000 processos judiciais sobre saúde no Brasil em 2011. Trata-se de uma pesquisa nacional sobre o Judiciário brasileiro, com a finalidade de monitoramento das ações judiciais em saúde. Os dados foram disponibilizados no site do CNJ. ${ }^{7}$ A respeito das instituições jurídicas como espaço de diálogo entre sociedade civil e Estado, ver Asensi (2010; 2013).

${ }^{8}$ Logicamente, isto não quer dizer que esta judicialização esteja isenta de qualquer viés de classe. Pelo contrário, em função dos obstáculos culturais e socioeconômicos do direito à saúde, é possível observar que a judicialização é colonizada predominantemente por um perfil de classe média. Portanto, de modo algum é possível afirmar que a judicialização é uma estratégia frequente em todas as classes sociais, tampouco se expressa da mesma forma nas diversas regiōes do Brasil.

${ }^{9}$ Em Portugal, a utilização de protestos foi uma das principais estratégias da sociedade civil para se relacionar com o Estado na reivindicação de seus direitos. A via judicial, a despeito de toda a similaridade institucional e jurídica com o Brasil, recebeu pouco destaque no processo de efetivação do direito à saúde. São autores que investigaram a prática de protestos em Portugal: Mendes (2005), Mendes \& Seixas (2005), Seixas (2005), Duarte (2007) e Matos (2011). 
Health, the Judiciary and society: an analysis of Brazil and Portugal

This paper aims to discuss strategies and ways of realization of health as a right, to reflect on the limits and possibilities of using state and non-state mechanisms for their claim in Brazil and Portugal. To this end, we conducted qualitative and quantitative research to compare challenges for ensuring the right to health with a focus on access to justice and the repertoires of collective action. The results show that the complexity of the election of state or non-state mechanism is strongly related to the legal culture of citizens, as well as political and economic factors arising from the structure of opportunities for each of the locations.

> Key words: Judiciary; right to health; collective action; judicialization of health. 